\title{
Research Paper: Role of the Orexinergic System Within the Ventral Tegmental Area in the Development of Sensitization to Morphine Induced by Lateral Hypothalamus Stimulation
}

\author{
Amir Haghparast ${ }^{1 *}$ (D), Mina Rashvand ${ }^{2}$ (I) \\ 1. School of Dentistry, International Branch of Shahid Beheshti University of Medical Sciences, Tehran, Iran. \\ 2. Neuroscience Research Center, School of Medicine, Shahid Beheshti University of Medical Sciences, Tehran, Iran.
}

\begin{tabular}{|c|c|}
\hline $\begin{array}{l}\text { Use your device to scan } \\
\text { and read the article online }\end{array}$ & Citat on Haghparast, A., Rashvand, M. (2021). Role of the Orexinergic System Within the Ventral Tegmental Area in the \\
\hline 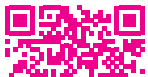 & $\begin{array}{l}\text { Development of Sensitization to Morphine Induced by Lateral Hypothalamus Stimulation. Basic and Clinical Neuroscience, } \\
\text { 13(1), 97-106. http://dx.doi.org/10.32598/bcn.2021.2946.1 }\end{array}$ \\
\hline 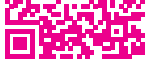 & dol'http://dx.doi.org/10.32598/bcn.2021.2946.1 \\
\hline
\end{tabular}

\section{(i) (3)}

Article info:

Received: 05 Oct 2020

First Revision: 06 Oct 2020

Accepted: 08 Oct 2020

Available Online: 01 Jan 2022

Keywords:

Morphine, Orexin, Lateral hypothalamus, Ventral tegmental area, Acute pain, Rat

\section{A B S T RA C T}

Introduction: The Lateral Hypothalamus (LH) has long been known to implicate the addictive behaviors of drug abuse. The Ventral Tegmental Area (VTA) is a major area of the mesolimbic system that is strongly involved in developing morphine sensitization. The current study aimed to examine the role of intra-VTA orexin receptors in the LH stimulation-induced sensitization to the antinociceptive response of morphine.

Methods: A total of 114 adult male Wistar rats underwent unilateral implantation of two separate cannulae in the LH and VTA using the stereotaxic apparatus. Intra-VTA administration of the Orexin-1 (OX1) and Orexin-2 (OX2) receptor antagonists, SB334867 and TCS OX2 29 ( 1,3 , and $10 \mathrm{nM} / 0.3 \mu \mathrm{L}$ DMSO), respectively, was performed 5 min before concurrent microinjection of carbachol $(250 \mathrm{nM} / 0.5 \mu \mathrm{L}$ saline $)$ into the $\mathrm{LH}$ and an ineffective dose of morphine $(0.5 \mathrm{mg} / \mathrm{kg}$; SC) during a 3-day sensitization period. After a 5-day free drug period, on the ninth day, for assessing the morphine sensitization, the nociceptive response was measured before and after morphine injection $(1 \mathrm{mg} / \mathrm{kg}$; SC) using the tail-flick test.

Results: The results revealed that the concurrent administration of carbachol $(250 \mathrm{nM})$ and an ineffective dose of morphine significantly induced morphine sensitization. Besides, the blockade of OX1 and OX2 receptors within the VTA before intra-LH carbachol injection attenuated morphine sensitization.

Conclusion: These findings suggest that LH stimulation potentiates the sensitization to morphine antinociceptive responses via affecting orexin receptors located in the VTA. However, OX1 receptors contribute more than OX2 receptors in the VTA to morphine sensitization in rats.

\footnotetext{
* Corresponding Author: 


\section{Highlights}

- LH stimulation enhances sensitization to the ineffective dose of morphine

- Intra-VTA OX1 receptor involves in morphine sensitization-induced by LH stimulation

- Intra-VTA OX2 receptor involves in morphine sensitization-induced by LH stimulation

\section{Plain Language Summary}

Behavioral sensitization, such as sensitization to the antinociceptive response of drugs, which defines as an enhanced systemic reaction to the same dose of addictive drugs, occurs in response to continuous and intermittent administration of these drugs. The Lateral Hypothalamus (LH) sends the orexinergic projections to the various regions of the brain and stimulation of LH induces sensitization to the antinociceptive response of morphine. The Ventral tegmental area (VTA) is a region of the brain that is strongly involved in developing morphine sensitization and receives orexinergic projections of LH. The current study aimed to examine the role of orexin receptors within the VTA in the LH stimulation-induced sensitization to the antinociceptive response of morphine in rats. In this study orexin-1 (OX1) and orexin-2 (OX2) receptors within the VTA region were blocked using their antagonists. After five minutes chemical stimulation of LH was done using carbachol microinjection into this area and ineffective dose of morphine was injected subcutaneously. These interventions were done for three consecutive days as sensitization period. After a 5-day free drug period, on the ninth day, for assessing the morphine sensitization, the nociceptive response was measured. The results revealed that the concurrent administration of LH stimulation and an ineffective dose of morphine significantly induced morphine sensitization. Besides, the blockade of OX1 and OX2 receptors within the VTA before LH stimulation attenuated sensitization to the antinociceptive response of morphine. Therefore, the orexinergic system plays an important role in morphine sensitization and can be considered as one of the potential targets to increase the analgesic effect of morphine.

\section{Introduction}

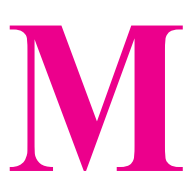

orphine is a valuable drug in the clinic for its analgesic properties. Morphine use is, however, limited because of its addictive nature. Development of behavioral sensitization, defined as an enhanced systemic reaction to the same dose of morphine or any other addictive substance, occurs in response to continuous and intermittent administration of these drugs in rodents (Lv et al., 2019; Reisi, Bani-Ardalan, Zarepour, \& Haghparast, 2014; Vezina \& Leyton, 2009). Several neurotransmitters and neuromodulators are involved in opioid-induced behavioral sensitization, including dopamine (Charmchi, Zendehdel, \& Haghparast, 2016), glutamate (Sepehrizadeh, Sahebgharani, Ahmadi, Shapourabadi, Bozchlou, \& Zarrindast, 2008), serotonin (Pang et al., 2016), and orexin (Łupina et al., 2018; Razavi, Karimi, Bani-Ardalan, \& Haghparast, 2014). The Ventral Tegmental Area (VTA) and Nucleus Accumbens (NAc) play a predominant role in developing morphine sensitization via dopamine receptor activation (Reisi et al., 2014). Orexinergic neurons located in the Lateral Hypothalamus (LH) evoke their effects via two metabotropic receptors: Orexin receptor type 1 (OX1) and Orexin receptor type 2 (OX2), which are widely distributed in the various brain areas (Marcus \& Elmquist, 2006; Sakurai et al., 1998). The lateral hypothalamus sends orexinergic projections all over the mesolimbic dopaminergic pathway such as VTA (Fadel \& Deutch, 2002), a cerebral region that is highly involved in behavioral sensitization (Borgland, Taha, Sarti, Fields, \& Bonci, 2006), and chemical stimulation of LH has been shown to involve in pain modulation via acting on orexin receptors located in this area (Ezzatpanah, Babapour, \& Haghparast, 2016). Generally, the mesocorticolimbic pathway is a dopaminergic projection derived from VTA into the NAc and the prefrontal cortex, which participates in addictive behaviors (Stott \& Ang, 2013). Our laboratory's prior work revealed that chemical stimulation of LH potentiated morphine sensitization in the Conditioned Place Preference (CPP) paradigm through the OX1 receptors located in the VTA region in rats' brain (Razavi et al., 2014). Although many studies have been performed in the context of morphine sensitization, few have indicated the alterations of antinociceptive effects of morphine in morphine-sensitized animals (Zarrindast, Asgari-Afshar, \& Sahebgharani, 2007). So 
considering that the mesolimbic dopamine system has a crucial role in the induction of morphine sensitization and given the distribution of orexinergic projections all over the mesolimbic system, including the VTA, it seems essential to study the role of $\mathrm{LH}$ in the induction of sensitization to morphine antinociceptive responses and the potential role of intra-VTA OX1 and OX2 receptors in this phenomenon.

\section{Methods}

Study animals

A total of 114 adult male Wistar rats (Pasteur Institute, Tehran, Iran; 220-250 gr) were randomly chosen and assigned into 18 groups ( $\mathrm{n}=6-8$ in each group). Animals were maintained in a 12/12 h light/dark cycle with food and water ad libitum. All experimental protocols were carried out in accordance with the Guide for the Care and Use of Laboratory Animals (National Institutes of Health Publication No. 80-23, revised 1996) and were confirmed by the Research and Ethics Committee of Shahid Beheshti University of Medical Sciences (IR. SBMU.PHNS.REC.1398.133), Tehran, Iran.

\section{Surgical preparation}

The animals were anesthetized with Intraperitoneal (IP) administration of xylazine $2 \%(10 \mathrm{mg} / \mathrm{kg})$ and ketamine $10 \%(100 \mathrm{mg} / \mathrm{kg})$ mixture and placed in a stereotaxic instrument (Stoelting, USA). Two stainless steel guide cannulae (23-gauge, $11 \mathrm{~mm}$ in length) were implanted unilaterally (right or left side) into the LH and VTA injection sites and anchored with a steel screw. The incision was closed with dental cement. The coordinates for the VTA region according to the Paxinos and Watson rat brain atlas (Paxinos \& Watson, 1982) were as follows: Anteroposterior $(\mathrm{AP})=4.8 \mathrm{~mm}$ caudal to bregma, Lateral to midline (Lat) $= \pm 0.9 \mathrm{~mm}$, Dorsoventral (DV) $=8.3 \mathrm{~mm}$ ventral from the skull surface. Also, the coordinates for $\mathrm{LH}$ were as follows: $\mathrm{AP}=-2.92 \mathrm{~mm}$, Lat $=$ $\pm 1 \mathrm{~mm}$ and $\mathrm{DV}=8.1 \mathrm{~mm}$ ventral to the skull surface. Rats were then allowed to recover for one week before the beginning of experiments.

\section{Drugs and drug administration}

In this study, the following drugs were used: morphine sulfate dissolved in $0.9 \%$ sterile saline (Temad, Tehran, Iran), different solutions $(62.5,125$, and $250 \mathrm{nM})$ of carbachol (Sigma-Aldrich, USA), which were dissolved in $0.5 \mu \mathrm{L}$ saline. Different doses of $\operatorname{SB} 334867(1,3$, and $10 \mathrm{nM}$ ) as an OX1 receptor antagonist or TCS OX2 29
$(1,3$, and $10 \mathrm{nM})$ as an $\mathrm{OX} 2$ receptor antagonist (Tocris Bioscience, Bristol, UK) were dissolved in $0.3 \mu \mathrm{L}$ dimethyl sulfoxide 12\% (DMSO; Sigma-Aldrich, Germany) as a vehicle of both orexin receptor antagonists. All drugs or vehicle solutions were infused slowly over 60 s. All microinjections were conducted in animals via a stainless-steel injector (30-gauge needle) connected to a $1-\mu \mathrm{L}$ Hamilton syringe via a polyethylene tube (PE-20).

\section{Tail-flick test}

In this study, morphine sensitization was assessed by the antinociceptive response of morphine. The nociceptive response was measured using the tail-flick apparatus (Harvard Apparatus, USA). A thermal stimulus was applied in succession 3,5 , or $7 \mathrm{~cm}$ from the caudal tip of the tail. An automatic sensor detected the tail-flick response and reaction time between the onset of the thermal stimulus and tail-flick response recorded as TailFlick Latency (TFL). The rats were tested before and 5, 15 , and $30 \mathrm{~min}$ after morphine injection $(1 \mathrm{mg} / \mathrm{kg}$; SC). The obtained value of each TFL time was calculated on the average of two consecutive tail-flick tests at each time point. The radiant heat intensity was manually set at $45 \%$ of the maximum intensity that yields baseline TFL values in 3-4 s. A cut-off time of $10 \mathrm{~s}$ was applied to avoid tissue damage.

The TFL value was expressed as a percentage of maximal possible effect (\%MPE), calculated as follows:

$\% \mathrm{MPE}=\frac{\text { Post-drug administration latency }(\mathrm{s})-\text { Baseline latency }(s)}{\text { Cut-off value }(\mathrm{s})-\text { Baseline latency }(\mathrm{s})} \times 100$

\section{Experimental design}

Briefly, animals received intra-LH carbachol after intra-VTA OX1/OX2 receptor antagonists, followed by an ineffective dose of morphine $(0.5 \mathrm{mg} / \mathrm{kg}$; SC) for 3 consecutive days as a sensitization period. Then, after five days of free drug administration, on the ninth day, the tail-flick test was performed before and after the morphine (1 mg/kg; SC) injection (Figure 1).

The effect of morphine injection during sensitization period on the induction of morphine sensitization

To understand the effect of morphine ( $5 \mathrm{mg} / \mathrm{kg}$; SC) administration for three consecutive days (sensitization period) on the development of morphine sensitization, the rats received saline $(1 \mathrm{~mL} / \mathrm{kg} ; \mathrm{SC})$ or morphine $(5$ $\mathrm{mg} / \mathrm{kg}$; SC) during sensitization period. After five days of free drug administration, on the ninth day, the tailflick test was performed before and after morphine in- 


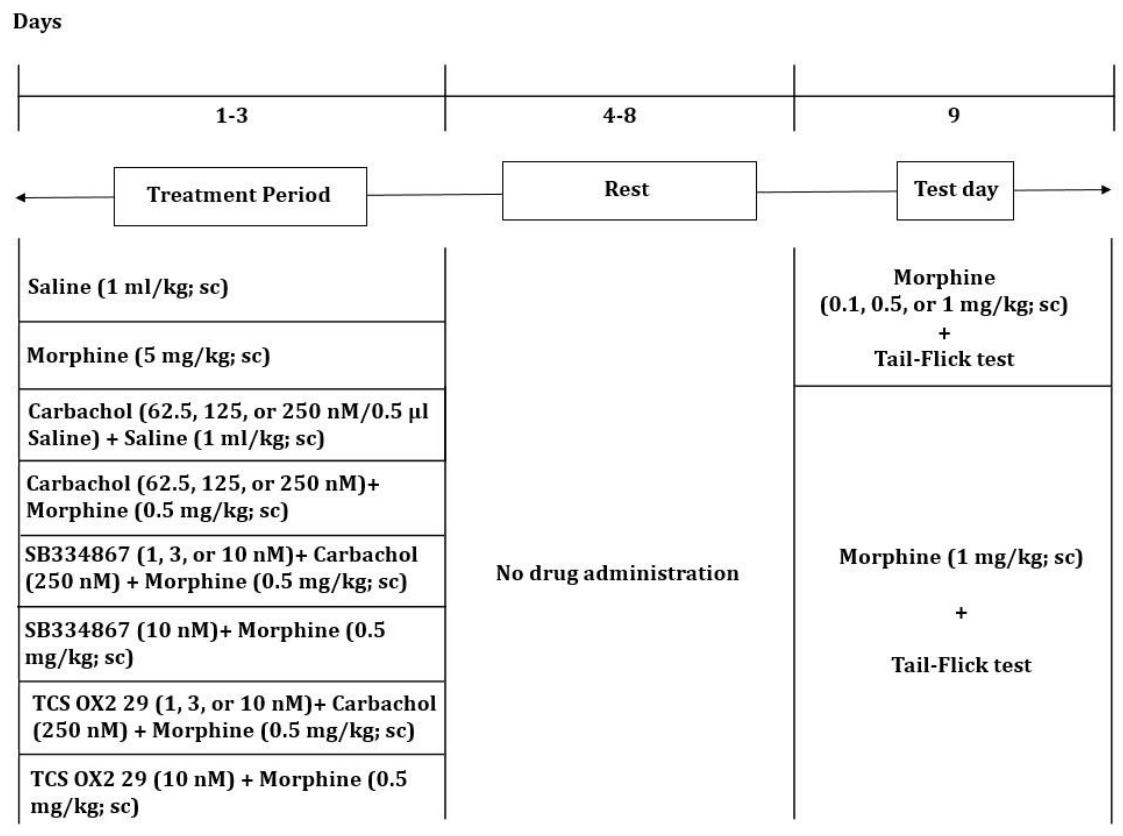

Figure 1. A Schematic timeline of the experimental protocol

NEUR SCIENCE

Carbachol was dissolved in $0.5 \mu \mathrm{L}$ saline and was microinjected into the lateral hypothalamus region in the rat's brain. SB334867 and TCS OX2 29 were dissolved in $0.3 \mu \mathrm{L}$ DMSO $(12 \%)$ and were microinjected into the ventral tegmental area region in the rat's brain.

TF: Tail-Flick; SC: Subcutaneous.

jection. To determine the appropriate dose of morphine for induction of morphine sensitization, different doses of morphine $(0.1,0.5$, and $1 \mathrm{mg} / \mathrm{kg} ; \mathrm{SC})$ were injected before the tail-flick test.

The effect of co-administration of carbachol and ineffective dose of morphine during the sensitization period on the induction of morphine sensitization

To elucidate the role of intra-LH administration of carbachol in the development of morphine sensitization, during a 3-day sensitization period, different doses of carbachol $(62.5,125$, and $250 \mathrm{nM} / 0.5 \mu \mathrm{L}$ saline $)$ were microinjected just before the injection of saline $(1 \mathrm{~mL} / \mathrm{kg}$; SC) or the ineffective dose of morphine $(0.5 \mathrm{mg} / \mathrm{kg}$; SC) during sensitization period. After five days of free drug administration, on the ninth day, the tail-flick test was performed before and after the morphine (1 mg/kg; SC) injection.

The role of OX1 and OX2 receptors within the VTA in the LH stimulation-induced morphine sensitization

In this set of experiments, different doses of SB334867 $(1,3$, and $10 \mathrm{nM})$ as an OX1 receptor antagonist or TCS OX2 29 (1, 3, and $10 \mathrm{nM} / 0.3 \mu \mathrm{L}$ DMSO) as an OX2 receptor antagonist were microinjected 5 minutes before concurrent administration of the ineffective dose of morphine $(0.5 \mathrm{mg} / \mathrm{kg}$; SC) and intra-LH administra- tion of the highest dose of carbachol $(250 \mathrm{nM} / 0.5 \mu \mathrm{L}$ saline) during 3-day sensitization period to evaluate the role OX1 and OX2 receptors within the VTA in the LH stimulation-induced morphine sensitization. After five days of free drug administration, on the ninth day, a tailflick test was performed before and after the morphine (1 $\mathrm{mg} / \mathrm{kg}$; SC) injection.

\section{Histological verification}

After completing the experiments, the animals were anesthetized with a ketamine and xylazine mixture. Animals were then transcardially perfused with $0.9 \%$ normal saline and formaldehyde solution (10\%). After removing the rat brains, $50-\mu \mathrm{m}$ transverse brain sections were prepared, and the location of the guide cannula tips was compared with the VTA coordinates in the rat brain atlas (Paxinos $\&$ Watson, 2006). The animals with the wrong cannulae placements were excluded from the data analysis.

\section{Statistical analysis}

All statistical analyses were performed using commercially available software GraphPad Prism ${ }^{\circledR} \quad 6.0$ (GraphPad Software, CA, USA). Data were expressed as mean \pm SEM (standard error of the mean). The obtained \%MPE at any time set intervals in all groups were subjected to a 1-way Analysis of Variance (ANOVA) 

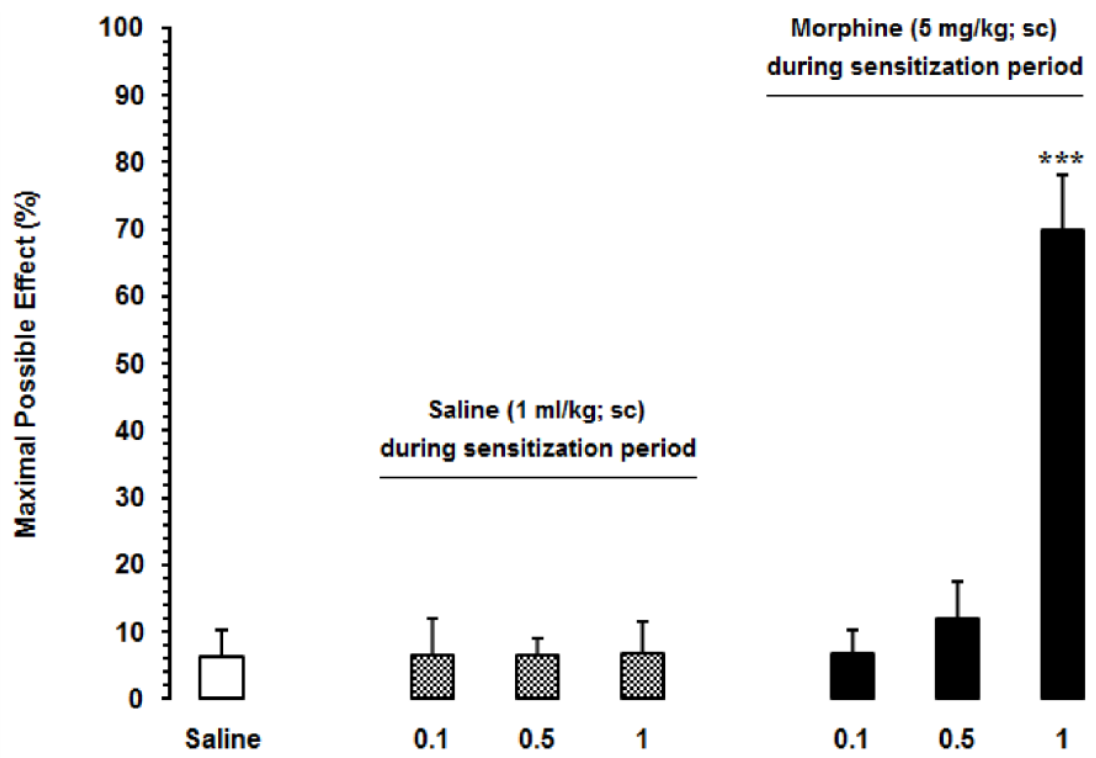

NEUR:SCIENCE

Figure 2. Effect of morphine administration during the sensitization period on the induction of morphine sensitization measured by Tail-Flick Test

Three consecutive days (sensitization period) of morphine administration $(5 \mathrm{mg} / \mathrm{kg}$; SC) followed by five days of no drug administration enhanced sensitization to the antinociceptive response of morphine $(1 \mathrm{mg} / \mathrm{kg}$; SC). The percentage mean of maximal possible effect (\%MPE) was considered an antinociceptive index. Injection of saline instead of morphine did not induce morphine sensitization at any doses of morphine. Each point shows the mean \pm SEM for seven rats in each group.

*** $\mathrm{P}<0.001$ compared to the saline-control group.

followed by the Dunnett or Newman-Keuls multiple comparisons test. $\mathrm{P}$ values less than 0.05 were considered significant statistically.

\section{Results}

The effect of morphine injection during sensitization period on the induction of morphine sensitization

One-way ANOVA followed by the Dunnett test $\left(\mathrm{F}_{6,48}=\right.$ 21.51, $\mathrm{P}<0.0001$; Figure 2) showed that morphine administration $(5 \mathrm{mg} / \mathrm{kg}$; SC) for three consecutive days (sensitization period) enhanced sensitization to the antinociceptive response of morphine in animals which received morphine $1 \mathrm{mg} / \mathrm{kg}$ but not 0.1 or $0.5 \mathrm{mg} / \mathrm{kg}$ before the tail-flick test. Thus, $1 \mathrm{mg} / \mathrm{kg}$ of morphine was selected as the appropriate dose for the rest of the experiments. The mean percentage of maximal possible effect (\%MPE) was considered an antinociceptive index. As shown in Figure 2, saline (1 mL/kg; SC) administration instead of morphine $(5 \mathrm{mg} / \mathrm{kg}$; SC) during the sensitization period could not induce morphine sensitization in animals that received different doses of morphine $(0.1$, 0.5 , or $1 \mathrm{mg} / \mathrm{kg}$; SC) before the nociceptive test.
The effect of concomitant administration of carbachol and morphine during the sensitization period on the induction of morphine sensitization

One-way ANOVA followed by the Newman-Keuls multiple comparisons test indicated that intra-LH microinjection of carbachol (125 and $250 \mathrm{nM} / 0.5 \mu \mathrm{L}$ saline) just before injection of an ineffective dose of morphine $(0.5 \mathrm{mg} / \mathrm{kg}$; SC) during the sensitization period enhanced sensitization to the antinociceptive response of morphine $\left(\mathrm{F}_{3,23}=16.63, \mathrm{P}<0.0001\right.$; Figure 3, right panel). In contrast, $62.5 \mathrm{nM}$ of carbachol could not induce morphine sensitization. As shown in Figure 3, 1-way ANOVA followed by the Dunnett test $\left(\mathrm{F}_{3,26}=0.1277, \mathrm{P}=0.9427\right.$; Left panel) indicated that concurrent administration of saline $(1 \mathrm{~mL} / \mathrm{kg}$; SC) and different doses of intra-LH carbachol $(62.5,125$, and $250 \mathrm{nM} / 0.5 \mu \mathrm{L}$ saline) for three consecutive days could not induce sensitization to the antinociceptive response of morphine $(1 \mathrm{mg} / \mathrm{kg}$; SC) measured by the tail-flick test.

The effect of Intra-VTA Injection of OX1 receptor antagonist, SB334867 on the LH stimulationInduced morphine sensitization 


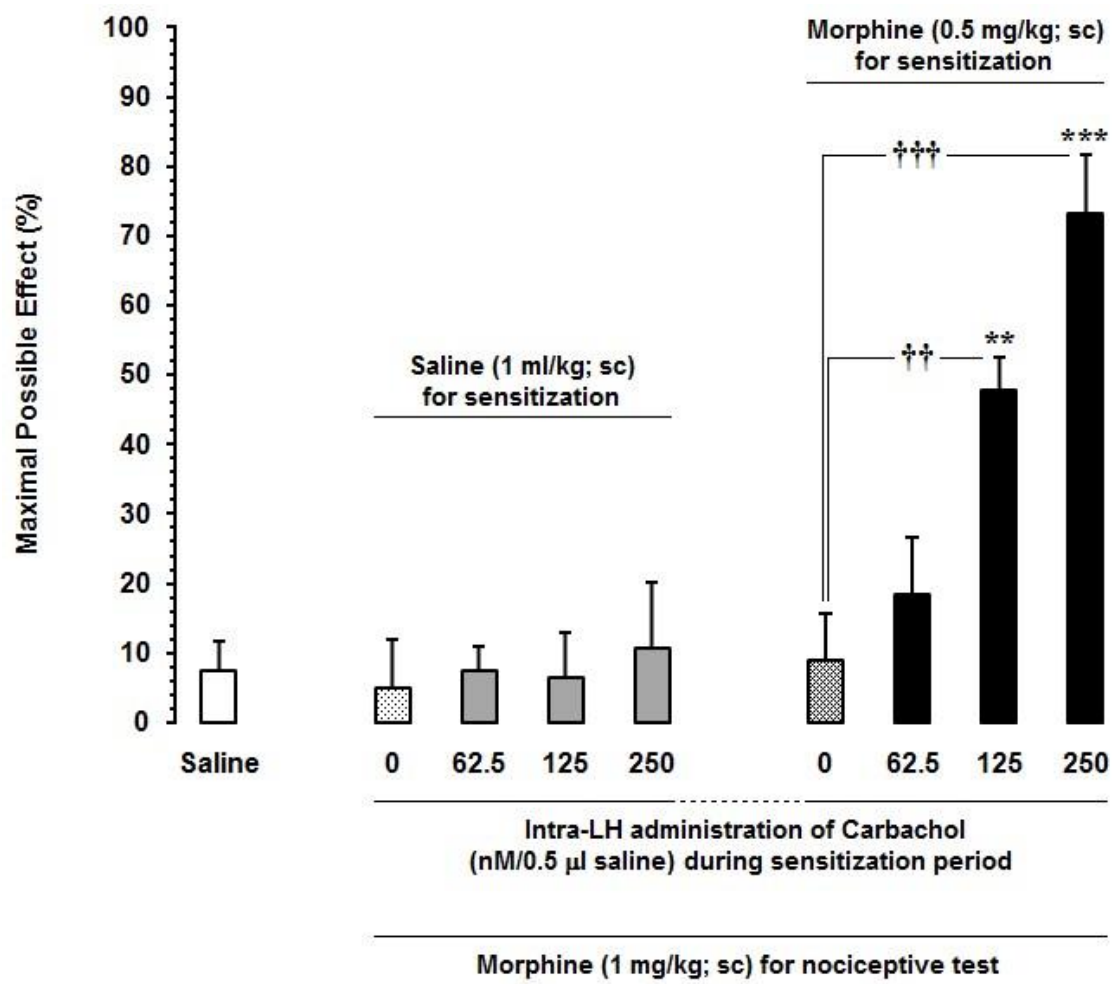

NEUR:SCIENCE

Figure 3. Effect of chemical stimulation of the Lateral Hypothalamus (LH) by carbachol before morphine injection during sensitization period on the induction of morphine sensitization measured by Tail-Flick Test

Intra-LH microinjection of carbachol just before injection of an ineffective dose of morphine $(0.5 \mathrm{mg} / \mathrm{kg}$; SC) during the sensitization period (right panel) enhanced sensitization to the antinociceptive response of morphine. In contrast, concurrent administration of saline ( $1 \mathrm{~mL} / \mathrm{kg}$; SC) and different doses of intra-LH carbachol during the sensitization period (left panel) could not induce morphine sensitization. Each point shows the Mean \pm SEM for 6-7 rats in each group.

$\mathrm{P}<0.01$ and ${ }^{* * *} \mathrm{P}<0.001$ compared to the saline-control group. $\mathrm{P}<0.01$ and $\mathrm{t}+\mathrm{P}<0.001$ compared to the respective vehicle groups.

One-way ANOVA followed by the Dunnett test indicated that the blockade of OX1 receptors within the VTA by SB334867 before intra-LH microinjection of carbachol could decrease the morphine sensitizationinduced by co-administration of carbachol $(250 \mathrm{nM} / 0.5$ $\mu \mathrm{L}$ saline $)$ and ineffective dose of morphine $(0.5 \mathrm{mg} / \mathrm{kg}$; $\mathrm{SC})\left(\mathrm{F}_{5,41}=14.37, \mathrm{P}<0.0001\right.$; Figure 4). However, intraVTA administration of the highest dose of SB334867 (10 nM/0.3 $\mu \mathrm{L}$ DMSO) alone did not induce morphine sensitization measured by the tail-flick test. Moreover, statistical analysis showed that intra-VTA administration of SB334867 (3 and $10 \mathrm{nM} / 0.3 \mu \mathrm{L}$ DMSO) could block the morphine sensitization induced by carbachol microinjection compared to the group which received intraVTA DMSO instead of SB334867 (Figure 4).

The effect of Intra-VTA injection of OX2 receptor antagonist, TCS OX2 29 on the LH stimulationinduced morphine sensitization
As shown in Figure 5, one-way ANOVA followed by the Dunnett test indicated that intra-VTA microinjection of OX2 receptor antagonist, TCS OX2 29 before co-administration of carbachol $(250 \mathrm{nM} / 0.5 \mu \mathrm{L}$ saline $)$ and ineffective dose of morphine could decrease the morphine sensitization $\left(\mathrm{F}_{5,40}=16.5, \mathrm{P}<0.0001\right.$; Figure 5). However, intra-VTA administration of the highest dose of TCS OX2 29 (10 nM/0.3 $\mu \mathrm{L}$ DMSO) alone did not induce morphine sensitization. Besides, 1-way ANOVA showed that only the highest dose of TCS OX2 29 (10 $\mathrm{nM} / 0.3 \mu \mathrm{L}$ DMSO) could block the morphine sensitization induced by carbachol microinjection compared to the group which received intra-VTA DMSO instead of TCS OX2 29 in this set of experiments (Figure 5).

\section{Discussion}

The current study demonstrates the contribution of OX1 and OX2 receptors within the VTA in morphine sensitization induced by LH's chemical stimulation before the subcutaneous injection of the ineffective dose of 

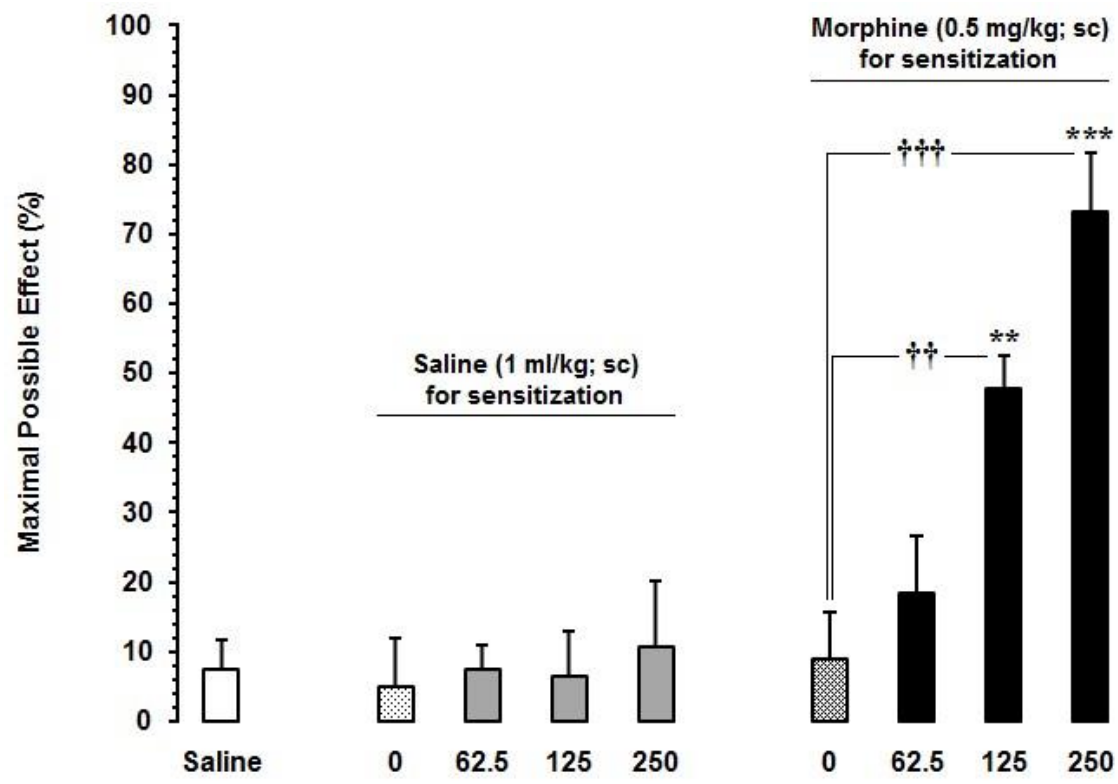

Intra-LH administration of Carbachol ( $\mathrm{nM} / 0.5 \mu \mathrm{l}$ saline) during sensitization period

Morphine (1 mg/kg; sc) for nociceptive test

Figure 4. The effect of intra-VTA injection of SB334867 on the morphine sensitization-induced by co-administration of carbachol and morphine

Intra-VTA administration of OX1 receptor antagonist, SB334867 before co-administration of intra-LH carbachol ( $250 \mathrm{nM} / 0.5 \mu \mathrm{L}$ saline) and ineffective dose of morphine $(0.5 \mathrm{mg} / \mathrm{kg}$; SC) during the sensitization period could decrease the morphine sensitization-induced by concurrent administration of carbachol and morphine. Morphine sensitization was measured by the tail-flick test. Each point shows the Mean \pm SEM for 7 rats in each group.

${ }^{* *} \mathrm{P}<0.01$ and ${ }^{* * *} \mathrm{P}<0.001$ compared to the saline-control group. $\dagger \mathrm{P}<0.05$ and $\mathrm{\dagger}+\mathrm{P}<0.001$ compared to the DMSO group.

morphine. The significant findings of this study were as follows: 1) concurrent microinjection of carbachol into the LH and subcutaneous injection of morphine for three consecutive days as the sensitization period, enhanced sensitivity to the antinociceptive effects of morphine; 2) blockade of the $O X 1$ and $O X 2$ receptors within the VTA during sensitization period, significantly reduced the morphine sensitization induced by co-administration of carbachol and morphine, and 3) The contribution of OX1 receptors in the VTA was more predominant than that of $\mathrm{OX} 2$ receptors to morphine sensitization.

The present study indicates that subcutaneous injection of morphine $(5 \mathrm{mg} / \mathrm{kg}$ ) for three consecutive days followed by five days of free-morphine administration induced sensitization to the antinociceptive response of morphine ( $1 \mathrm{mg} / \mathrm{kg}$ but not morphine 0.1 or $0.5 \mathrm{mg}$ / $\mathrm{kg}$ ). In this respect, certain similar studies indicated that repeated administration of morphine $(5 \mathrm{mg} / \mathrm{kg}$; $\mathrm{SC}$ ) for three consecutive days followed by five days of washout increased antinociceptive responses of morphine $(1 \mathrm{mg} /$ $\mathrm{kg}$ ) in sensitized animals (Charmchi et al., 2016; Molaei, Sanati, Zaringhalam, \& Haghparast, 2014; Reisi et al., 2014). On the other hand, it has been reported that repeated morphine administration $(20 \mathrm{mg} / \mathrm{kg}$; IP) for seven days (Roeckel et al., 2017) or a regimen of three days of morphine $(20 \mathrm{mg} / \mathrm{kg}$; IP) followed by a five days washout led to opioid-induced hyperalgesia in mice (Ahmadi, Golbaghi, Azizbeigi, \& Esmailzadeh, 2014). This discrepancy stems from the dosage and duration of morphine administration. The obtained results also showed that intra-LH microinjection of carbachol for three consecutive days followed by five days of no drug administration could not potentiate morphine sensitization, while co-administration of intra-LH carbachol and ineffective dose of morphine $(0.5 \mathrm{mg} / \mathrm{kg}$; SC) during the sensitization period enhanced sensitivity to the antinociceptive response of morphine. Previously it has been shown that chemical stimulation of LH potentiated morphine sensitization in the CPP paradigm (Razavi et 

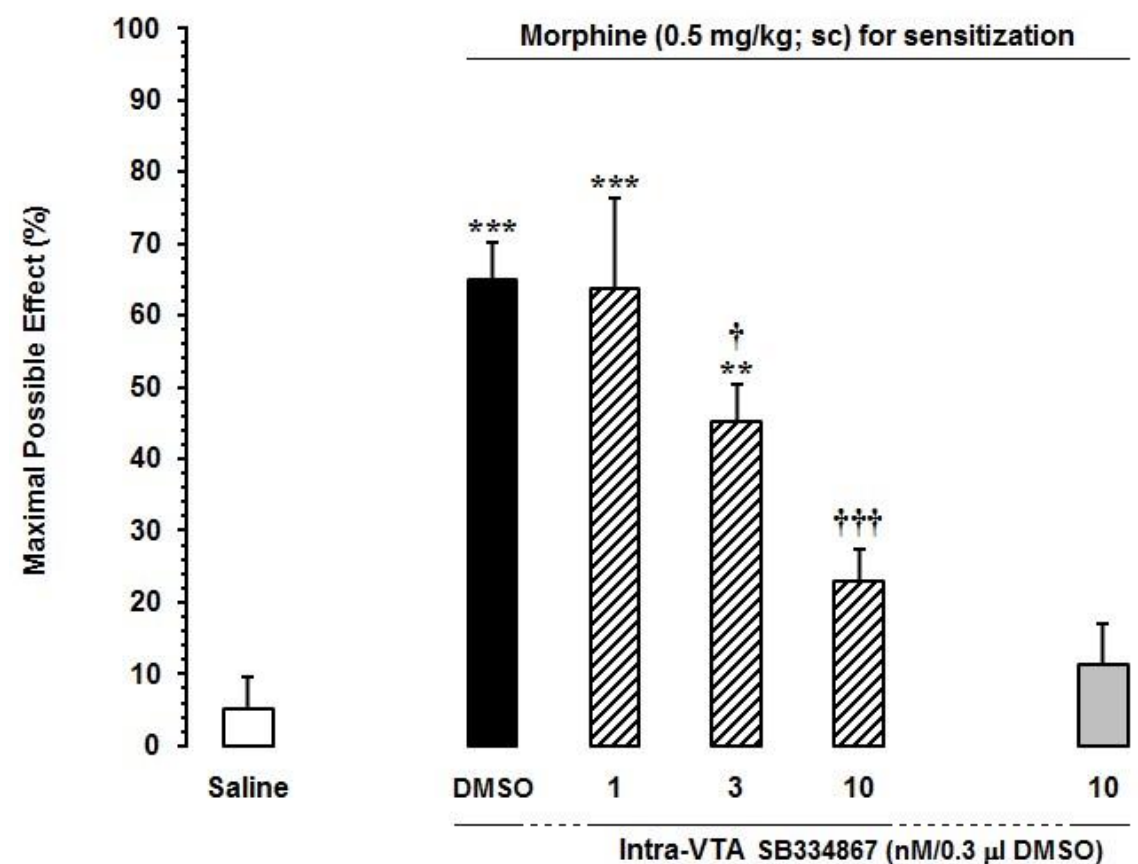

Intra-LH administration of Carbachol

( $250 \mathrm{nM} / 0.5 \mu \mathrm{l}$ saline)

NEUR SCIENCE

Figure 5. The effect of intra-VTA injection of TCS OX2 29 on the morphine sensitization-induced by co-administration of carbachol and morphine

Intra-VTA administration of OX2 receptor antagonist, TCS OX2 29 (10 nM/0.3 $\mu \mathrm{L}$ DMSO) before co-administration of intra-LH carbachol $(250 \mathrm{nM} / 0.5 \mu \mathrm{L}$ saline) and ineffective dose of morphine $(0.5 \mathrm{mg} / \mathrm{kg}$; SC) during the sensitization period could decrease the morphine sensitization by concurrent administration of carbachol and morphine. Morphine sensitization was measured by the tailflick test. Each point shows the Mean \pm SEM for 6-8 rats in each group.

${ }^{*} \mathrm{P}<0.05$ and ${ }^{* * *} \mathrm{P}<0.001$ compared to the saline-control group. $\dagger \mathrm{P}<0.05$ compared to the DMSO group.

al., 2014), and orexinergic neurons of the LH, and not nearby Melanin-Concentrating Hormone $(\mathrm{MCH})$ neurons, have $\mu$-opioid receptors and implicate in the addictive behaviors in response to chronic morphine administration (Georgescu et al., 2003). Intracerebroventricular (ICV) injection of SB-334867 as a selective OX1 receptor antagonist before subcutaneous injection of morphine has been reported to decrease morphine-induced antinociceptive response in formalin test (Azhdari-Zarmehri, Esmaeili, Sofiabadi, \& Haghdoost-Yazdi, 2013). Steiner et al. reported that blockade of both orexin receptors by oral gavage of almorexant decreased morphine-induced sensitization to the locomotor activity in sensitized rats (Steiner, Lecourt, \& Jenck, 2013). Therefore, some effects of morphine administration mediate by orexin receptors. The results of the present study revealed that chemical stimulation of LH induced morphine sensitization by affecting

OX1 and OX2 receptors within the VTA. There is a dense projection of orexin neurons from the $\mathrm{LH}$ to the dopaminergic and non-dopaminergic neurons in the VTA. Accordingly, single-unit extracellular and wholecell patch-clamp recordings indicated that orexin depolarizes these neurons and increases the firing frequency of either group of neurons (Korotkova, Sergeeva, O. A., Eriksson, Haas, \& Brown, 2003). Functional interplay between orexin and dopamine neurons of the mesolimbic system has been reported to implicate rewarding effects and hyperlocomotion induced by morphine (Narita et al., 2006).

Several lines of the study reveal that the induction of drug sensitization is not only associated with the release of dopamine (Lv et al., 2019; Stout et al., 2016) but is also pertinent to the alterations in the sensitivity of dopamine receptors in the mesolimbic structures, including the NAc, VTA, striatum, and hippocampus (for review, see Listos, Łupina, Talarek, Mazur, Orzelska-Górka, \& Kotlińska, 2019). Besides, the blockade of dopamine receptors within the VTA and NAc prevents sensitization to the antinociceptive response of morphine (Reisi et al., 
2014). It has been reported that the levels of dopamine and its major metabolites in the NAc are markedly increased by intra-VTA administration of both orexin A and orexin B (Narita et al., 2006). Moreover, orexin A can induce its antinociceptive response by activating intraVTA orexinergic receptors, which activate the dopaminergic inputs to the NAc in rats (Yazdi-Ravandi, Razavi, Haghparast, Goudarzvand, \& Haghparast, 2014). It has been demonstrated that microglial activation following chronic administration of morphine leads to disruption of the VTA dopaminergic circuitry (Taylor et al., 2016). Besides, Glial Fibrillary Acidic Protein (GFAP), an important marker of astrocyte activation, increased the striatum and the prefrontal cortex in morphine sensitized rats. However, intraperitoneal administration of SB-334867 reversed these alterations (Lupina et al., 2018). So it seems that the interaction of orexin and the mesolimbic dopamine system plays a crucial role in inducing sensitization to the antinociceptive response of morphine.

\section{Conclusion}

Summing up, this study confirms and extends the contribution of OX1/OX2 receptors within the VTA in sensitization to the antinociceptive response of morphineinduced by concomitant intra-LH administration of carbachol and subcutaneous injection of morphine.

\section{Ethical Considerations}

\section{Compliance with ethical guidelines}

All experimental protocols were carried out in accordance with the Guide for the Care and Use of Laboratory Animals (National Institutes of Health Publication No. 80-23, revised 1996) and were confirmed by the Research and Ethics Committee of Shahid Beheshti University of Medical Sciences (IR.SBMU.PHNS.REC.1398.133), Tehran, Iran.

\section{Funding}

The Vice-Chancellor for Research and Technology of Shahid Beheshti University of Medical Sciences supported this work (Grant no. 98-21484-1398/12/20).

\section{Authors' contributions}

Conceptualization: Amir Haghparast; Methodology: Amir Haghparast; Investigation: Amir Haghparast; Writing - original draft: Mina Rashvand, Amir Haghparast; Writing - review \& editing: Mina Rashvand, Amir Haghparast; Funding Acquisition, Resources, Supervision: Amir Haghparast.

\section{Conflict of interest}

The authors declared no conflict of interest.

\section{Acknowledgments}

The authors would also like to thank the Dental School, Shahid Beheshti University of Medical Sciences, for the cooperation in carrying out this study.

\section{References}

Ahmadi, S., Golbaghi, H., Azizbeigi, R., \& Esmailzadeh, N. (2014) $\mathrm{N}$-methyl-D-aspartate receptors involved in morphine-induced hyperalgesia in sensitized mice. European Journal of Pharmacology, 737, 85-90. [DOI:10.1016/j.ejphar.2014.04.048] [PMID]

Azhdari-Zarmehri, H., Esmaeili, M. H., Sofiabadi, M., \& Haghdoost-Yazdi, H. (2013). Orexin receptor type-1 antagonist SB334867 decreases morphine-inducedantinociceptive effect in formalin test. Pharmacology Biochemistry and Behavior, 112, 64-70. [DOI:10.1016/j.pbb.2013.09.018] [PMID]

Borgland, S. L., Taha, S. A., Sarti, F., Fields, H. L., \& Bonci, A. (2006). Orexin A in the VTA is critical for the induction of synaptic plasticity and behavioral sensitization to cocaine. Neuron, 49(4), 589-601. [DOI:10.1016/j.neuron.2006.01.016] [PMID]

Charmchi, E., Zendehdel, M., \& Haghparast, A. (2016). The effect of forced swim stress on morphine sensitization: Involvement of D1/D2-like dopamine receptors within the nucleus accumbens. Progress in Neuro-Psychopharmacology and Biological Psychiatry, 70, 92-9. [DOI:10.1016/j.pnpbp.2016.05.006] [PMID]

Ezzatpanah, S., Babapour, V., \& Haghparast, A. (2016). Differ ential contribution of orexin receptors within the ventral tegmental area to modulation of persistent inflammatory pain European Journal of Pain (United Kingdom), 20(7), 1090-101. [DOI:10.1002/ejp.833] [PMID]

Fadel, J., \& Deutch, A. Y. (2002). Anatomical substrates of orexin-dopamine interactions: Lateral hypothalamic projections to the ventral tegmental area. Neuroscience, 111(2), 379-87. [DOI:10.1016/S0306-4522(02)00017-9]

Georgescu, D., Zachariou, V., Barrot, M., Mieda, M., Willie, J. T., Eisch, A. J., et al. (2003). Involvement of the lateral hypothalamic peptide orexin in morphine dependence and withdrawal. Journal of Neuroscience, 23(8), 3106-11. [DOI:10.1523/ jneurosci.23-08-03106.2003] [PMID] [PMCID]

Korotkova, T. M., Sergeeva, O. A., Eriksson, K. S., Haas, H. L., \& Brown, R. E. (2003). Excitation of ventral tegmental area dopaminergic and nondopaminergic neurons by orexins/ hypocretins. Journal of Neuroscience, 23(1), 7-11. [DOI:10.1523/ jneurosci.23-01-00007.2003] [PMID] [PMCID]

Listos, J., Łupina, M., Talarek, S., Mazur, A., Orzelska-Górka, J., \& Kotlińska, J. (2019). The mechanisms involved in morphine addiction: An overview. International Journal of Molecular Sciences, 20(17), 4302. [DOI:10.3390/ijms20174302] [PMID] [PMCID] 
Łupina, M., Tarnowski, M., Baranowska-Bosiacka, I., Talarek, S., Listos, P., Kotlińska, J., et al. (2018). SB-334867 (an orexin-1 receptor antagonist) effects on morphine-induced sensitization in micea view on receptor mechanisms. Molecular Neurobiology, 55(11) 8473-85. [DOI:10.1007/s12035-018-0993-] [PMID] [PMCID]

Lv, Y., Hu, R. R., Jing, M., Zhao, T. Y, Wu, N., Song, R., et al. (2019). Selective dopamine D3 receptor antagonist YQA14 inhibits morphine-induced behavioral sensitization in wild type, but not in dopamine D3 receptor knockout mice. Acta Pharmacologica Sinica, 40(5), 583-8. [DOI:10.1038/s41401-0180153-0] [PMID] [PMCID]

Marcus, J. N., \& Elmquist, J. K. (2006). Orexin projections and localization of orexin receptors. In S. Nishino, \& $\mathrm{T}$, Sakurai (Eds.), The Orexin/Hypocretin System: Physiology and Pathophysiology (pp. 21-43). Totowa: Springer. [DOI:10.1385/1-59259-950-8:21] [PMID] [PMCID]

Molaei, M., Sanati, M. H., Zaringhalam, J., \& Haghparast, A. (2014). Microinjection of WIN55,212-2 as a cannabinoid agonist into the basolateral amygdala induces sensitization to morphine in rats. Basic and Clinical Neuroscience, 5(4), 295-302. [PMID] [PMCID]

Narita, M., Nagumo, Y., Hashimoto, S., Narita, M., Khotib, J., Miyatake, M., et al. (2006). Direct involvement of orexinergic systems in the activation of the mesolimbic dopamine pathway and related behaviors induced by morphine. Journal of Neuroscience, 26(2), 398-405. [DOI:10.1523/JNEUROSCI.2761-05.2006] [PMID] [PMCID]

Pang, G., Wu, X., Tao, X., Mao, R., Liu, X., Zhang, Y. M., et al. (2016). Blockade of serotonin 5-HT2A receptors suppresses behavioral sensitization and naloxone-precipitated withdrawal symptoms in morphine treated mice. Frontiers in Pharmacology, 7(DEC), 514. [DOI:10.3389/fphar.2016.00514]

Paxinos, G., \& Watson, C. (2006). The rat brain in stereotaxic coordinates: Hard Cover Edition (Vol. 2006). Amsterdam: Elsevier. https://www.google.com/books/edition/The_Rat_ Brain_in_Stereotaxic_Coordinates $/ 0 \mathrm{prYfd}=\mathrm{en} \& \mathrm{gbpv}=0$

Razavi, Y., Karimi, S., Bani-Ardalan, M., \& Haghparast, A. (2014) Chemical stimulation of the lateral hypothalamus potentiated the sensitization to morphine in rats: Involvement of orexin-1 receptor in the ventral tegmental area. EXCLI Journal, 13, 112030. [DOI:10.17877/DE290R-7236] [PMID] [PMCID]

Reisi, Z., Bani-Ardalan, M., Zarepour, L., \& Haghparast, A. (2014). Involvement of D1/D2 dopamine receptors within the nucleus accumbens and ventral tegmental area in the development of sensitization to antinociceptive effect of morphine. Pharmacology Biochemistry and Behavior, 118, 16-21. [DOI:10.1016/j.pbb.2013.12.023] [PMID]

Roeckel, L. A., et al. (2017). Morphine-induced hyperalgesia involves mu opioid receptors and the metabolite morphine3-glucuronide. Scientific Reports, 7, 10406. [DOI:10.1038/ s41598-017-11120-4]

Sakurai, T., Amemiya, A., Ishii, M., Matsuzaki, I., Chemelli, R. M., Tanaka, H., et al. (1998). Orexins and orexin receptors: A family of hypothalamic neuropeptides and $\mathrm{G}$ protein-coupled receptors that regulate feeding behavior. Cell, 92(4), 573-85. [DOI:10.1016/S0092- 8674(00)80949-6] [PMID]

Sepehrizadeh, Z., Sahebgharani, M., Ahmadi, S., Shapourabadi, M. B., Bozchlou, S. H., \& Zarrindast, M. R. (2008). Morphineinduced behavioral sensitization increased the mRNA ex- pression of NMDA receptor subunits in the rat amygdala Pharmacology, 81(4), 333-43. [DOI:10.1159/000122959] [PMID]

Steiner, M. A., Lecourt, H., \& Jenck, F. (2013). The dual orexin receptor antagonist almorexant, alone and in combination with morphine, cocaine and amphetamine, on conditioned place preference and locomotor sensitization in the rat. International Journal of Neuropsychopharmacology, 16(2), 417-32. [DOI:10.1017/S1461145712000193] [PMID]

Stott, S. R. W., \& Ang, S. L. (2013). Chapter 23 - The generation of midbrain dopaminergic neurons. In J. L. R. Rubenstein, \& P. Rakic (Eds.), Comprehensive Developmental Neuroscience: Patterning and Cell Type Specification in the Developing CNS and PNS (pp. 435-53). Amsterdam: Elsevier Science. [DOI:10.1016/B978-0-12-397265-1.00099-X]

Stout, K. A., Dunn, A. R., Lohr, K. M., Alter, S. P., Cliburn, R A., Guillot, T. S., et al. (2016). Selective enhancement of dopamine release in the ventral pallidum of methamphetaminesensitized mice. ACS Chemical Neuroscience, 7(10), 1364-73. [DOI:10.1021/acschemneuro.6b00131] [PMID] [PMCID]

Taylor, A. M. W., Castonguay, A., Ghogha, A., Vayssiere, P., Pradhan, A. A. A., Xue, L., et al. (2016). Neuroimmune regulation of GABAergic neurons within the ventral tegmental area during withdrawal from chronic morphine. Neuropsychopharmacology, 41(4), 949-59. [DOI:10.1038/npp.2015.221] [PMID] [PMCID]

Vezina, P., \& Leyton, M. (2009). Conditioned cues and the expression of stimulant sensitization in animals and humans. Neuropharmacology, 56(Suppl. 1), 160-8. [DOI:10.1016/j.neuropharm.2008.06.070] [PMID] [PMCID]

Yazdi-Ravandi, S., Razavi, Y., Haghparast, A., Goudarzvand, M., \& Haghparast, A. (2014). Orexin A induced antinociception in the ventral tegmental area involves D1 and D2 receptors in the nucleus accumbens. Pharmacology Biochemistry and Behavior, 126, 1-6. [DOI:10.1016/j.pbb.2014.08.009] [PMID]

Zarrindast, M. R., Asgari-Afshar, A., \& Sahebgharani, M. (2007). Morphine-induced antinociception in the formalin test: Sensitization and interactions with D1 and D2 dopamine receptors and nitric oxide agents. Behavioural Pharmacology, 18(3), 177-84. [DOI:10.1097/FBP.0b013e32813c5462] [PMID] 